\section{Compilation of the Checklist for Cultivars of Salix L. (Willow)}

\author{
Yulia A. Kuzovkina ${ }^{1,2}$ \\ Department of Plant Science and Landscape Architecture, Unit-4067, \\ University of Connecticut, Storrs, CT 06269-4067
}

Additional index words. nomenclature, ICRA, IPC, variety, subspecies, form, epithet

\begin{abstract}
The long history of Salix $\mathbf{L}$. cultivation has resulted in selections of cultivars with superior technical and ornamental characteristics. Numerous cultivars have been developed and named over the centuries, but until now, no comprehensive compilation of these records has ever been made. With the expanding domestication of the genus Salix and the active selection of new cultivars, it is increasingly important that we have clear and standardized records documenting the cultivars. In 2013, the International Poplar Commission of the Food and Agriculture Organization (IPC FAO) was appointed as the International Cultivar Registration Authority (ICRA) for willows. The Checklist for Cultivars of Salix was compiled as the first step toward the promotion of a standardized registration process and the establishment of a Cultivar Register for Salix. Eight hundred and fifty four cultivar epithets with accompanying information have been included in the Checklist. The largest group of cultivars-more than 200 - is represented by basket selections. This is followed by selections for ornamental plantings and biofuel production. The Checklist aims to promote the uniformity and accuracy of cultivar names of Salix, and provides a baseline for new registrations to ensure that each newly developed cultivar receives a unique, authoritative botanical name.
\end{abstract}

The genus Salix L. (Salicaceae Mirb., willow) comprises $\approx 450$ species (Argus, 2010) with numerous subspecies, varieties, forms, natural and artificial hybrids, and cultivars. Genus diversity and a wide natural distribution from the tropics to the arctic zones have promoted extensive cultivation of willows around the world, resulting in the accumulation of significant technical knowledge about the genetic resources of Salix. Numerous selections of cultivars with superior technical and ornamental characteristics have been chosen deliberately and applied to various purposes: as stock for basket and cricket bat manufacturing, as sources of chemical compounds such as tannin and salicin, as forage for livestock, for honey production, as ornamentals, and for amenity plantings (Kuzovkina et al., 2008). Most recently, Salix has become an important source for bioenergy production and for various ecosystem services (Rowe et al., 2009; Volk et al., 2006). Many specialized institutions and programs have been founded worldwide that continuously release new clones with improved characteristics (Stanton et al., 2014). As new cultivars enter into commercial production, clear and standardized records of the described genotypes are becoming increasingly important.

The "IPC FAO" of the United Nations, has held the ICRA for poplars since 1953 and maintains the Cultivar Registrar of Populus L. The scope of the "IPC FAO" was expanded to willows in 2013 (Isebrands and Richardson,

Received for publication 1 Apr. 2015. Accepted for publication 3 Sept. 2015.

${ }^{1}$ Associate Professor.

${ }^{2}$ Corresponding author. E-mail: jkuzovkina@uconn. edu.
2014); effective in July 2013, The Special Commission for Cultivar Registration of the International Society for Horticultural Sciences designated the IPC FAO as the ICRA for Salix, the official body for the registration of willow cultivars (Kuzovkina and Vietto, 2014). The primary objective of cultivar registration is to provide an accessible list of cultivar epithets informing the scientific community of the attributes of available genetic material.

The Checklist for Cultivars of Salix containing all cultivars described previously will serve as the baseline for the registration of new cultivars. Its compilation was defined as the most urgent first step in the establishment of a uniform registration process (Kuzovkina and Vietto, 2014). The Checklist functions as a reference that will help prevent the repetition of existing names in a denomination class; it also assures that new names adhere to the rules of the International Code of Nomenclature for Cultivated Plants (ICNCP) (Brickell et al., 2009).

The objective of this study was to compile a synopsis of all cultivar epithets that have been present in the public domain, accompanied by relevant information for each name entry, including the name status (accepted, synonym, unresolved, etc.), bibliography, distinctive characters, and a description of the standard specimen.

Publications. A thorough search of horticultural, botanical, and commercial literature was conducted to find relevant information concerning ornamental and technical cultivars. The literature search included prominent horticultural references of the late 19th, 20th, and 21 st centuries (Bailey, 1924; Bailey and Bailey, 1976; Bean, 1980; Dirr, 2009;

\section{Materials and Methods}

Hillier, 2014; Krussmann, 1978, 1984; Rehder, 1927, 1940, 1949; Späth, 1930, etc.), as well as systematic monographs on Salix (Meikle, 1984; Ohashi, 2000, 2001; Skvortsov, 1968, 1999), and horticultural editions dedicated to Salix (Newsholme, 1992; Stott, 2001; Warren-Wren, 1972). Also, reviewed were horticultural magazines, conference proceedings, nursery catalogs, and various online publications, as well as the two major databases of surveys of names in contemporary nursery catalogs - the List of Names of Woody Plants: International Standard, European Nurserystock Association 2010-15 (Hoffman, 2010) and the Royal Horticultural Society Horticultural Database (2015). In addition, the Community Plant Variety Office and US Patent and Trademark Office (US PTO) were searched for Salix cultivar names that were filed and registered with these offices. Technical sources, such as the IPC FAO National Country Reports, were analyzed to extract data on willow cultivars. The total number of cited references in the Checklist includes 78 sources.

Nomenclature. The correct names at the species level were listed in accordance with The Plant List (2015), which "incorporates recent" taxonomic revisions of the genus based on unpublished data from the "World Checklist of Salicaceae sensu stricto" of the World Checklist of Dicotyledons (2015). Each cultivar name was verified to be in agreement with the latest edition of the ICNCP (Brickell et al., 2009). When discrepancies were found, a comment was included with the cultivar entry. A name was considered as "accepted" and listed in the Checklist in bold if a published reference was found, or if a cultivar name was filed and registered with the international and national patent offices, and thus self-established by a grant/patent, according to the ICNCP (Brickell et al., 2009).

References to the original botanical citations were provided for cultivars that were derived from naturally occurring botanical taxa at the rank of subspecies, variety, or form. Synonymy of botanical records was listed in chronological order to reflect consequent changes in ranks.

\section{Results and Discussion}

The Checklist of 854 cultivars may be viewed at the website of the "International Poplar Commission (2015)." The Checklist begins with a cultivar name index that lists all cultivar epithets in alphabetical order. This index provides a tool for effective retrieval of cultivar epithets and enables the new, proposed epithets to be quickly verified against this reference, to avoid repetition. This index is followed by the main body of the Checklist, in which cultivar epithets are grouped alphabetically under the respective species names, which are also arranged in alphabetical order.

Statistics. Out of the 854 names, 734 were designated as "accepted" and listed in boldface print. Ninety-six names lacking published references were listed in lightface; most of these names were found in nursery catalogs. Eighteen 
names were recorded as synonymous; these are also listed in lightface. A few names were recorded as "unresolved" when no conclusive nomenclature was found. The largest numbers of cultivar names were found for $S$. triandra $\mathrm{L}$. (71), S. alba L. (65), S. purpurea L. (64), and S. $\times$ fragilis L. (52).

Nine trade designations were included in the Checklist, where they are written in the ICNCP recommended styling to avoid the use of these epithets in the names of cultivars. Six of them-S. BLACK CAT ${ }^{\text {TM }}$, $S$. KILMARNOCK, $S$. MAGICAL SILVER ${ }^{\text {TM }}$, $S$. PRAIRIE REFLECTION ${ }^{T M}, S$. SCARLET CURLS $^{\circledR} ， S$. TORTUOSA GEEL ${ }^{\mathrm{TM}}$-were listed with an accepted cultivar name. Three designations - $S$. AUSTREE ${ }^{\circledR}, S$. CORAL SNAP $^{\mathrm{TM}}$, and $S$. SKYRISE ${ }^{\mathrm{TM}}$ - were listed with no alternative cultivar names.

Cultivar entries. It is desirable that every cultivar in the Checklist has a complete record, including a description, but for 189 names, descriptions could not be found. Also, not all cultivar descriptions were derived from authentic primary sources. Records describing type or standard specimens were found for only 35 names. Most taxa lacked records that are complete and accurate enough to prevent ambiguity in the name application.

Fourteen instances of the same cultivar name applied to more than one cultivar within the denomination class Salix were recorded. The use of eight of these names is permitted because they were established before 1 Jan. 1959: 'Angustifolia' (3 species), 'Aurea' (2 species), 'Elegantissima' (2 species), 'Lanceolata' (2 species), 'Pendula' (10 species), 'Regalis' (2 species), 'Russelliana' ( 2 species), and 'Variegata' (2 species). Six epithets lacked establishment dates. The ICNCP (Brickell et al., 2009) requires that names not be reused within a denomination class. However, to avoid confusion, it was recommended in the Checklist that these epithets be linked to the name of the species to which they apply.

Variation in Salix. The largest group of cultivars was represented by basket selections that proliferated during the culmination of the craft in the late 19th and early 20th centuries. More than 200 cultivar names were applied to selections of Salix taxa used for basket production based on their straight trunks, long stems, high flexibility, density, and color (Stott, 2001). Many of them remain important today as ornamental shrubs.

Cultivars selected on the basis of ornamental characteristics displayed: 1) improved growth habits for landscape use and amenity plantings-columnar, pendulous, compact, prostrate, or dwarf; 2) distinct floral buds or catkins; 3) bright coloration of stems, stem fasciation, and contortion; and 4) interesting leaf coloration - golden, pink, or variegated. Another extensive group of Salix cultivars included genotypes with superior technical characteristics for biofuel production and environmental applications. Novel clones with high yield and adaptive characteristics were described for cold and frost hardiness and resistance to leaf rust and insects, as well as improved wood quality in terms of viscosity, moisture content, density, and fiber length.
Polyclonal cultivars. The majority of these cultivars are genetically identical selections represented by a single clone and sex; but there are many recorded polyclonal cultivars that lack genetic uniformity. In some cases, they include hybrid cultivar complexes consisting of several segregates. For example, a hybrid cultivar complex described as $S$. $\times$ fragilis 'Basfordiana' is represented by many clones with orange-yellow stems, 14 of which have their own epithets. These clones originated as seedlings of the same hybrid combination - S. alba subsp. vitellina (L.) Schübl. \& G.Martens $\times S$. euxina I.V.Belyaeva.

Extensive cultivar complexes of polyclonal cultivars were also derived from botanical taxa. Forty-three recorded cultivars of Salix were derived from naturally occurring taxa at the rank of subspecies, variety, or form. For example, many clonal selections of $S$. alba subsp. vitellina (L.) Schübl. \& G. Martens have been brought into commercial trade, but they were all cultivated under the single cultivar name $S$. alba 'Vitellina'.

\section{Conclusions}

Publication of the Checklist for Cultivars of Salix L. (willow) aims to promote uniformity and accuracy of Salix cultivar names providing a baseline for new registrations to ensure that each developed cultivar receives a unique, authoritative, botanical name that has not been used before. The Checklist may be the most comprehensive single information resource related to the cultivars of willow. But it should be regarded as a working reference. It will be updated regularly with additional information and corrections of errors as more records are discovered and created. The Checklist will serve a diverse constituency of users including plant breeders, nursery professionals, horticulturists, plant records specialists, foresters, and gardeners. Its goal is to provide the foundation for stability in the denomination of Salix cultivars and to promote the effective utilization of germplasm.

\section{Literature Cited}

Argus, G.W. 2010. Salix. In: Flora of North America Editorial Committee (ed.). Flora of North America North of Mexico, Vol. 7, p. 23-162. Oxford University Press, New York and Oxford.

Bailey, L.H. 1924. Manual of cultivated plants: A flora for the identification of the most common or significant species of plants grown in the continental United States and Canada. The Macmillan Company, New York, NY.

Bailey, L.H. and E.Z. Bailey. 1976. Hortus third: A concise dictionary of plants cultivated in the United States and Canada. Revised and expanded by the staff of the Liberty Hyde Bailey Hortorium, Cornell Univ. Macmillan, New York, NY.

Bean, W.J. 1980. Trees and shrubs hardy in the British Isles, Vol. 4, p. 246-312. 8th ed. John Murray, London.

Brickell, C.D., C. Alexander, J.C. David, W.L.A. Hetterscheid, A.C. Leslie, V. Malecot, X. Jin, and J.J. Cubey (eds.). 2009. International code of nomenclature for cultivated plants (ICNCP). 8th ed. Scripta Horticulturae 10:1-184.

Dirr, M.A. 2009. Manual of woody landscape plants: Their identification, ornamental characteristics culture, propagation and uses. 6th ed. Stipes Publishing, Champaign, IL.
Hillier. 2014. The Hillier manual of trees and Shrubs. Royal Horticultural Society, London.

Hoffman, M.H.A. 2010. List of names of woody plants. International Standard, European Nurserystock Association (ENA) 2010-15, Lisse, Wageningen UR, p. 934.

International Poplar Commission. 2015. <http:// www.fao.org/forestry/ipc/en/>.

Isebrands, J.G. and J. Richardson (eds.). 2014. Poplars and willows: Trees for society and the environment (eds.). FAO UN and CABI.

Krussmann, G. 1978. Hanbuch der Laubegeholze. Paul Parey Verl, Berlin, Hamburg (in German).

Krussmann, G. 1984. Manual of cultivated broad-leaved trees and shrubs. Timber Press, Beaverton, OR.

Kuzovkina, Y.A. and L. Vietto. 2014. An update on the cultivar registration of Populus and Salix (Salicaceae). Skvortsovia 1:133-148.

Kuzovkina, Y.A., M. Weih, M. Abalos Romero, J. Charles, S. Hurst, I. McIvor, A. Karp, S. Trybush, M. Labrecque, T. Teodorescu, N.B. Singh, L. Smart, and T. Volk. 2008. Salix: Botany and global horticulture. HortReviews 34:447-489.

Meikle, R.D. 1984. Willows and poplars of Great Britain and Ireland. Botanical Society of the British Isles, London.

Newsholme, C. 1992. Willows: The genus Salix. B.T. Batsford Ltd., London.

Ohashi, H. 2000. A systematic enumeration of Japanese Salix (Salicaceae). J. Jpn. Bot. 75:1-41.

Ohashi, H. 2001. Saliceae of Japan. Science Reports of the Tohoku University, 4th series. Biology (Basel) 40:269-396.

Rehder, A. 1927. Manual of cultivated trees and shrubs. Macmillan, New York, NY.

Rehder, A. 1940. Manual of cultivated trees and shrubs. 2nd ed. Macmillan, New York, NY.

Rehder, A. 1949. Bibliography of cultivated trees and shrubs. Jamaica Plain, Massachusetts, New York

Rowe, R.L., N.R. Street, and G. Taylor. .2009. Identifying potential environmental impacts of largescale deployment of dedicated bioenergy crops in the UK. Renew. Sust. Energ. Rev. 13:271-290.

Royal Horticultural Society Horticultural Database. 2015. $<$ http://apps.rhs.org.uk/horticulturaldatabase/>.

Skvortsov, A.K. 1968. Willows of the USSR Nauka, Moscow, Russia. (in Russian).

Skvortsov, A.K. 1999. Willows of Russia and adjacent countries. Taxonomical and geographical revision. (English translation of 1968 Russian edition). University of Joensuu, Joensuu, Finland.

Späth, L. 1930. Spätbuch 1720-1930. BerlinBaumschulenweg, p. 656 (in German).

Stanton, B., M. Serapiglia, and L. Smart. 2014 The domestication and conservation of Populus and Salix genetic resources. In: J.G. Isebrands and J. Richardson (eds.) FAO. Poplar and Willow in the World: Meeting the needs of society and the environment. CABI

Stott, K.G. 2001. Cultivation and use of basket willow. Updated by B. Braster, R. Parfitt, S. Wynter, and R. Youdale. The Basketmakers Association and IACR - Long Ashton Research Station, UK.

The Plant List. 2015. <http://www.theplantlist.org/ tpl1.1/search?q=salix/>.

Volk, T.A., L.P. Abrahamson, C.A. Nowak, L.B. Smart, P.J. Tharakan, and E.H. White. 2006. The development of short-rotation willow in the northeastern United States for bioenergy and bioproducts, agroforestry and phytoremediation. Biomass Bioenergy 30:715-727.

Warren-Wren, S.C. 1972. The complete book of willows. A.S. Barnes and Company, New York, NY.

World Checklist of Dicotyledons. 2015. <http:// www.kew.org/science/directory/teams/Malpighiales/ projects.html>. 